03,09

\title{
Роль диффузии фотовозбужденных электронов из сильнолегированных слоев в фотопроводимости гетероструктур AIAs/GaAs
}

\author{
(C) Е.Е. Вдовин, Ю.Н. Ханин \\ Институт проблем технологии микроэлектроники и особо чистых материалов РАН, \\ Черноголовка, Россия \\ E-mail: vdov62@yandex.ru
}

Поступила в Редакцию 29 июля 2021 г.

В окончательной редакции 29 июля 2021 г.

Принята к публикации 4 августа 2021 г.

На основе исследования фотопроводимости в $p-i-n$-гетероструктурах GaAs/AlAs в видимом световом диапазоне показана доминирующая роль канала диффузии фотовозбужденных электронов из сильнолегированных слоев в процессе формирования осцилляций фототока от напряжения смещения и определяющий вклад этого канала в полный ток через структуру. Рассмотрена качественная модель транспорта возбужденных носителей, предполагающая диффузионный канал как основной источник фотоосцилляций.

Ключевые слова: гетероструктуры, фотопропроводимость.

DOI: $10.21883 /$ FTT.2021.12.51664.179

\section{1. Введение}

Полупроводниковые $p-i-n$-гетероструктуры широко используются в качестве детекторов излучения и имеют множество применений в оптоэлектронике [1-4]. Поглощение света с энергией больше ширины запрещенной зоны в таких полупроводниковых структурах приводит к генерации электронно-дырочных пар. Пары, созданные в обедненной $i$-области или на расстоянии порядка длины диффузии от $i$-области вглубь легированных $n$ - и $p$-слоев, разделяются электрическим полем, и в результате во внешней цепи появляется ток [4]. Величина фототока будет определяться дрейфовым током носителей, генерируемых в $i$-области, и диффузионными токами носителей, генерируемых за пределами $i$-области. При определенных условиях фотоотклик полупроводниковых структур может обнаруживать множество различных квантовых осцилляционных явлений. Например, релаксация энергии фотовозбужденных электронов и дырок из-за испускания оптических фононов приводит к осцилляциям фототока в зависимости от энергии возбуждающих фотонов [5]. Осцилляции фототока от напряжения смещения наблюдались в $p-i-n \mathrm{GaAs} / \mathrm{AlAs}$ или InGaN/GaN сверхрешетках $[6,7]$. В работе [8] было исследовано влияние слоя InAs квантовых точек в $i$-области $p-i-n$-диода на спектры фотоотклика и показана эффективность такой гетеросистемы для создания чувствительных фотоприемников. Позднее в подобных однобарьерных гетероструктурах GaAs/AlAs (см. рис. 1) были обнаружены гигантские осцилляции фототока $[9,10]$ при облучении светом с энергией фотона большей, чем ширина запрещенной зоны в GaAs, которые проявлялись как множественные резонансоподобные особенности на вольт-амперных характеристиках (BAX). Амплитуда таких осцилляций при этом составляла порядка $20 \%$ от средней величины фототока при облучении светом с длиной волны $\lambda=650 \mathrm{~nm}$, хотя в $p-i-n$-диодах с одиночным туннельным барьером априори невозможно предположить наличие каких либо резонансов фототока. Было обнаружено, что период этих осцилляций определяется исключительно длинной $i$-области, заключенной между AlAsбарьером и $p^{+}$-контактом. Эти осцилляции фототока были качественно интерпретированы в [9] как следствие модуляции темпа рекомбинации носителей в моменты совпадения уровней треугольной квантовой ямы, формирующейся в нелегированной прибарьерной $i$-области, с дном зоны проводимости высоколегированного $p^{+}$-слоя с изменением электрического поля. Схематическая зонная диаграмма активной области гетероструктуры при смещающем напряжении $V_{b}<1.5 \mathrm{~V}\left(V_{b} \approx 1.5 \mathrm{~V}\right.$ соответствует условию плоских зон) показана на рис. 1. Изменение $V_{b}$ в сторону отрицательных значений, начиная с $V_{b} \approx 1.5 \mathrm{~V}$, приводит к движению электронных уровней размерного квантования $E_{j}$ в треугольной квантовой яме (ТКЯ) вверх по энергии относительно ее дна, но вниз относительно края зоны проводимости $E_{\mathrm{C}}$, ограничивающего эту яму справа, приводя к последовательному вхождению в ТКЯ все новых уровней $E_{j}$ с энергией $\approx E_{\mathrm{C}}$ (см. рис. $1, a)$. По мере увеличения электрического поля в $i$-области конкретное электронное состояние $E_{j}$ в треугольной квантовой яме приближается к вершине этой треугольной потенциальной ямы, и его волновая функция все больше проникает в область с высокой плотностью основных дырок в легированном электроде $p^{+}$-GaAs. В модели из [9] предполагалось, что перекрытие увеличивает скорость рекомбинации фотовозбужденных электронов на $E_{j}$-уровне ТКЯ так, что снижает 

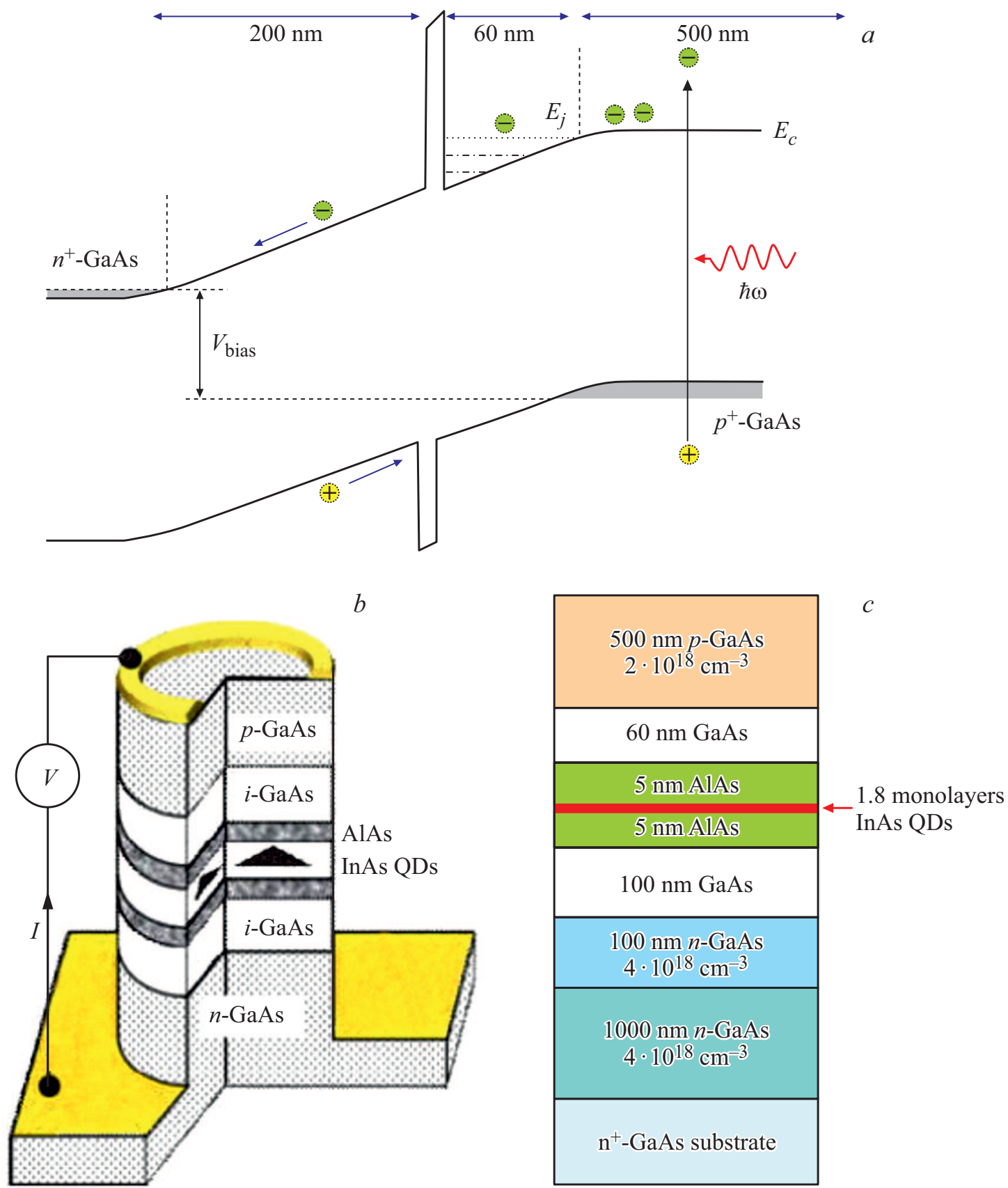

Рис. 1. a) Зонная диаграмма экспериментального образца при $V_{b}<1.5$ V. Стрелками показаны процессы фотогенерации электрондырочных пар и движения носителей в электрическом поле. Пунктирные линии - уровни размерного квантования $E_{j}$ в треугольной квантовой яме, а $E_{\mathrm{C}}-$ дно зоны проводимости в контактном $p^{+}$-слое; $b$ ) схематический разрез экспериментальной мезаструктуры и схема измерения фототока; $c$ ) схематическое представление последовательности, материалов и толщин слоев гетероструктуры с указанием концентраций легирования в контактных слоях.

их вклад в фототок при туннелировании через барьер AlAs. Следовательно, при изменении $V_{b}$ периодически изменяется скорость рекомбинации электронов, вызывая осцилляции фототока, то есть в моменты совпадения $E_{j}$ c $E_{\mathrm{C}}$ происходит резкое уменьшение фототока. Отметим, что в этой модели учитывается генерация электрондырочных пар только в области существования электрического поля, то есть в $i$-области, а возможный диффузионный ток электронов из $p^{+}$-области и дырок из $n^{+}$-области постулировался пренебрежимо малым, поскольку считается, что время диффузии носителей в $i$-область много больше, чем время жизни неосновного носителя в сильнолегированной $p^{+}$- (или $n^{+}$-) области. Это допущение противоречит общепринятому описанию фотодетектирования $p-i-n$-диодах [4], но поскольку было установлено, что период фотоосцилляций зави- 
сел только от ширины треугольной квантовой ямы, то такая модель достаточно правдоподобно описывала наблюдаемый эффект. Однако наши последующие исследования [11] показали, что зависимость отношения вкладов осциллирующей и неосциллирующей компонент фототока $I_{\text {osc }} / I_{\text {fon }}$ от мощности не может быть описана в рамках модели [9], где соотношение $I_{\text {osc }} / I_{\text {fon }}$ не зависит от интенсивности излучения и для согласованного описания всех представленных экспериментов была предложена новая качественная модель формирования осцилляций, включающая как основной элемент диффузионный транспорт фотовозбужденных электронов из р-слоя.

В данной работе изучено поведение осцилляций фототока в $p-i-n$-гетероструктурах GaAs/AlAs в видимом световом диапазоне длин волн. Показано, что осцилляции фототока от напряжения смещения образуются благодаря диффузии электронов, возбужденных светом в $p^{+}$-области и пришедших к краю треугольной квантовой ямы с энергией, совпадающей с верхним уровнем в яме; a величина неосциллирующей компоненты фототока определяется аддитивными вкладами токов носителей, возбуждаемых светом в остальных областях гетероструктуры. Рассмотрена качественная модель транспорта возбужденных носителей, предполагающая диффузионный канал как основной источник фотоосцилляций.

\section{2. Образцы и методика эксперимента}

Исследованные нами образцы были изготовлены на основе однобарьерных $p-i-n$-гетероструктур GaAs/AlAs с нелегированными $i$-слоями 60 и $100 \mathrm{~nm}$ со стороны $p^{+}$- и $n$-областей, соответственно, выращенных методом молекулярно-лучевой эпитаксии. Барьерный слой AlAs толщиной $5 \mathrm{~nm}$ расположен между нелегированными $i$-слоями.

Верхний $p^{+}$-слой $\mathrm{GaAs}$ толщиной $0.5 \mu \mathrm{m}$ легирован до концентрации $2 \cdot 10^{18} \mathrm{~cm}^{-3}$. Более детально такие структуры описаны в работах $[9,10]$. Для создания оптических мезаструктур диаметром 25-200 $\mu$ m применялась стандартная технология химического травления. На рис. 1,b схематически показан разрез экспериментальной мезаструктуры и схема измерения фототока, а на рис. $1, c-$ схематическое представление последовательности, материалов и толщин слоев гетероструктуры с указанием концентраций легирования в контактных слоях. Омические контакты изготавливались путем последовательного напыления слоев $\mathrm{AuGe} / \mathrm{Ni} / \mathrm{Au}$ и отжига при $T=400^{\circ} \mathrm{C}$. Вольт-амперные характеристики (BAX) были измерены при уровне шума менее $100 \mathrm{fA}$. Измерения проводились при температуре $4.2-100 \mathrm{~K}$. Образцы облучались светом с длинами волн в диапазоне $\lambda$ от 650 до $405 \mathrm{~nm}$ со стороны высоколегированной $p^{+}$-области. В качестве источников светового излучения в интервале длин волн $\lambda$ от 875 до $650 \mathrm{~nm}$ был использован спек- трофотометр, а в интервале от 650 до $405 \mathrm{~nm}$ набор светодиодов.

\section{3. Результаты исследований и их обсуждение}

На рис. 2 представлены обратные ветви ВАХ нашего экспериментального образца в области $V_{b}<1.5 \mathrm{~V}$ при 8 значениях мощности воздействующего излучения $P$ от 3 до $85 \mathrm{nW}$ с диной волны $\lambda=650 \mathrm{~nm}$ и при $T=4.2$ К. В отсутствие освещения обратные ветви ВАХ представляли собой монотонные зависимости без какихлибо видимых особенностей темновой ток в интервале до $3 \mathrm{~V}$ не превышал $10 \mathrm{pA}$ и, вероятно, определялся преимущественно процессами, аналогичными для тока генерации $p-n$-перехода. Воздействие на образцы световым излучением с $\lambda$ вплоть до $840 \mathrm{~nm}$ не оказывало сколь- нибудь заметного влияния на ВАХ. Когда же $\lambda$ становилась меньше $824 \mathrm{~nm}$ (что приблизительно соответствует ширине запрещенной зоны $\mathrm{GaAs}$ ), обратные

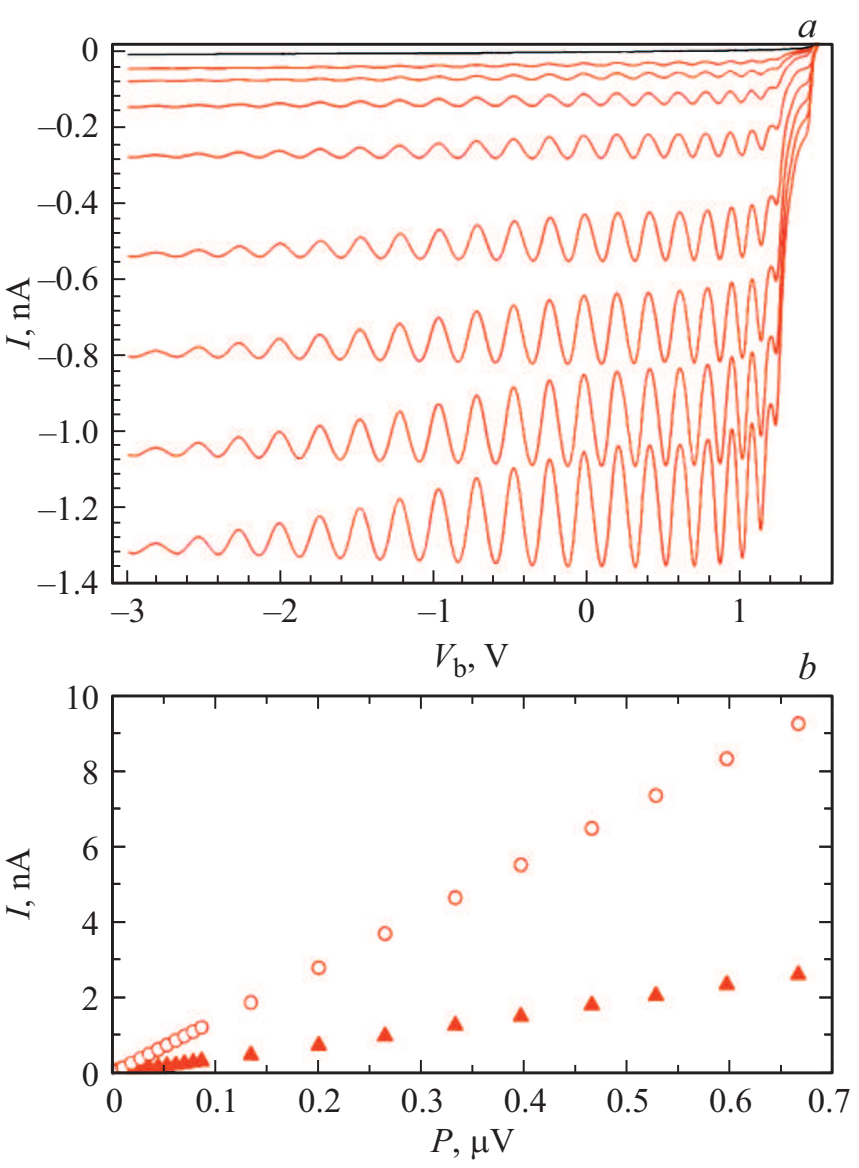

Рис. 2. a) ВАХ экспериментального образца в области $V_{b}<1.5 \mathrm{~V}$ при 8 значениях мощности воздействующего излучения $P=3,5,10,20,35,50,70,85 \mathrm{nW}$ с диной волны $\lambda=650 \mathrm{~nm}$ и при $T=4.2 \mathrm{~K} ; b)$ зависимость амплитуды $\left(I_{\max }-I_{\min }\right)$ и фонового тока $\left(I_{\max }+I_{\min }\right) / 2$ от мощности для осцилляции около $V_{b} \sim 0 \mathrm{~V}$ при $\lambda=650 \mathrm{~nm}$ и $T=4.2 \mathrm{~K}$. 

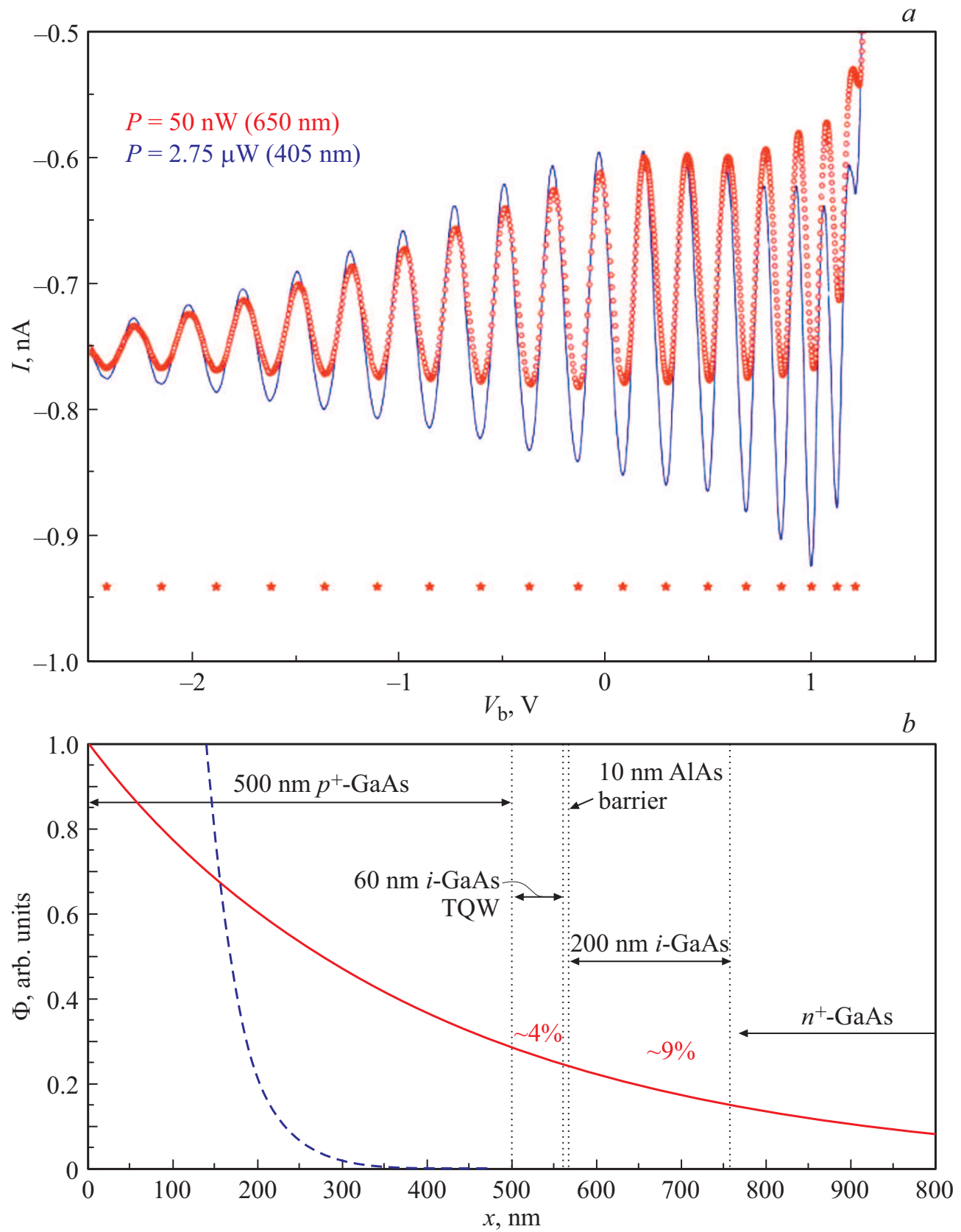

Рис. 3. a) ВАХ образца при освещении светом с $\lambda=650 \mathrm{~nm}$ (красные точки) при $P=50 \mathrm{nW}$ и $405 \mathrm{~nm}$ (фиолетовая линяя) при $P=2.75 \mu \mathrm{W}$ при $T=4.2 \mathrm{~K}$. Звездами отмечены положения по $V_{b}$ абсолютных значений максимумов фототока; $\left.b\right)$ кривые поглощения фотонов, рассчитанные по формуле $\Phi \propto \Phi_{0} \exp (-a x)$ для $\lambda=650 \mathrm{~nm}$ (красная кривая) и $405 \mathrm{~nm}$ (фиолетовая кривая) при $P_{405}=55 P_{650}$ вдоль слоев (по оси $x$ ) экспериментальной структуры.

ветви ВАХ начинали демонстрировать осциллирующую составляющую с амплитудой, пропорциональной $P$, и периодом, не зависящим от $\lambda$, аналогично [9]. Как амплитуда осцилляции, так и неосциллирующий „фоновый“ фототок линейно зависели от мощности излучения, как это видно на рис. $2, b$, где показана зависимость амплитуды $\left(I_{\max }-I_{\min }\right)$ и фонового тока $\left(I_{\max }+I_{\min }\right) / 2$ от мощности для осцилляции около $V_{b} \sim 0 \mathrm{~V}$ при $\lambda=650 \mathrm{~nm}$ и $T=4.2 \mathrm{~K}$. С уменьшением длины волны света фототок рос аналогично [8] до $\lambda \sim 750 \mathrm{~nm}$ с дальнейшим резким падением вплоть до $405 \mathrm{~nm}$, но зависимость амплитуды осцилляций и фонового тока от мощности продолжала оставаться линейной. На рис. 3,a- ВАХ образца при освещении светом с $\lambda=650 \mathrm{~nm}$ (красные точки) и $405 \mathrm{~nm}$ (фиолетовая линия). Мы можем видеть, что для того чтобы неосциллирующая компонента фототока для этих двух длин волн была примерно равна, необходимо увеличить мощность фиолетового света примерно в 55 раз относительно мощности красного света. Отметим, что амплитуда осцилляций фототока 
при этих условиях для $\lambda=405 \mathrm{~nm}$ примерно вдвое больше, чем для $\lambda=650 \mathrm{~nm}$. Мы обсудим это увеличение амплитуды фотоосцилляций ниже, а пока отметим, что в данном случае в рамках модели из работы [9], где учитывается генерация пар носителей только в $i$-области, существование осциллирующей компоненты фототока совершенно невозможно, вследствие того, что коэффициент поглощения света имеет спектральную зависимость и для фиолетового света составляет порядка $\alpha \sim 10^{5} \mathrm{~cm}^{-1}$ [12] так, что большинство фотонов поглощается вблизи поверхности образца, не доходя до треугольной квантовой ямы.

На рис. 3, $b$ показаны кривые поглощения фотонов $\Phi \propto \Phi_{0} \exp (-a x)$ для $\lambda=650 \mathrm{~nm}$ (красная кривая) и $405 \mathrm{~nm}$ (фиолетовая кривая) при $P_{405}=55 P_{650}$ и отложенные по оси $x$ слои нашей экспериментальной структуры. Для пояснения масштаба влияния $\lambda$ на глубину поглощения в нашей структуре отметим, что для $\lambda=405 \mathrm{~nm}$ менее $1 \%$ фотонов смогли бы пройти в глубину $p^{+}$-слоя на расстояние $0.2 \mu \mathrm{m}$, тогда как для $\lambda=650 \mathrm{~nm}$ та же доля фотонов проходит далеко в глубину $n^{+}$-слоя (до $\left.\sim 2 \mu \mathrm{m}\right)$, а порядка $15 \%$ проходит через оба $i$-слоя и достигает границы с $n^{+}$. Таким образом, наблюдение осцилляций фототока при $\lambda=405 \mathrm{~nm}$ уже явно указывает на непригодность модели их происхождения из [9] и необходимость ее пересмотра. Отметим при этом, что даже для красного света учет поглощения фотонов только в $i$-области нашей структуры дает низкую квантовую эффективность детектирования $<15 \%$, тогда как на подобной структуре в работе [8] была определена квантовая эффективность порядка 30-40\%, что указывает на необходимость учета дрейфа носителей из $p^{+}$- и $n^{+}$-областей и для $\lambda=650 \mathrm{~nm}$.

Мы предлагаем новую качественную модель, основанную на механизме резонансного усиления прохождения электронов, диффундирующих из глубины $p$-слоя через уровни в квантовой яме, аналогичном резонансному туннелированию через широкие КЯ [13]. Так как время жизни фотовозбужденных электронов вблизи поверхности мало, то большая их часть рекомбинирует прежде, чем они смогут достичь $i$-области с помощью диффузии и дать вклад в фототок. Но при большой мощности излучения достаточное количество электронов, которые генерируются в $p^{+}$-слое толщиной $0.5 \mu \mathrm{m}$, смогут продиффундировать до $i$-области и при совпадении с уровнем $E_{j}$ в треугольной КЯ протуннелировать через барьер резонансно, порождая осцилляции фототока. То есть каждый раз, когда с ростом электрического поля новый уровень $E_{j}$ входит в КЯ и совпадает с $E_{\mathrm{C}}$, происходит резкое резонансное увеличение темпа туннелирования через барьер электронов, возбужденных в глубине высоколегированного контактного $p^{+}$-слоя и дошедших в результате диффузии и дрейфа до края треугольной ямы, что и приводит к всплеску фототока. При этом амплитуда осцилляций определяется числом электронов, возбужденных светом в $p^{+}$-области и пришедших к краю треугольной квантовой ямы с
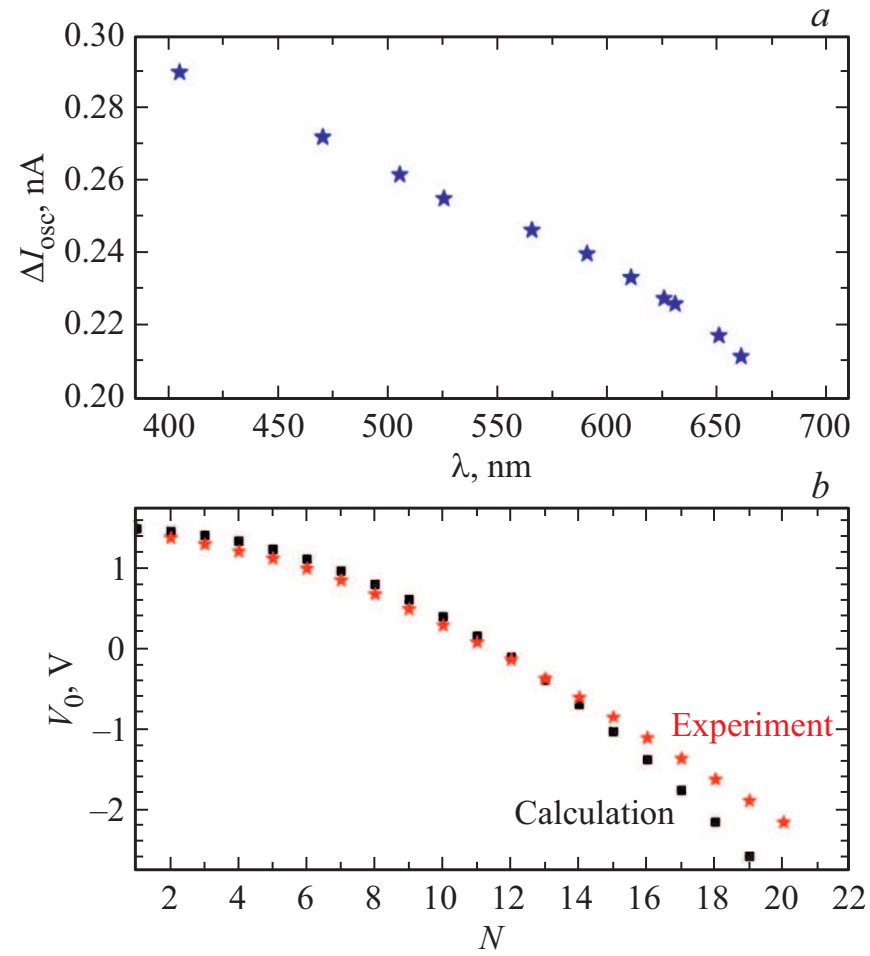

Рис. 4. $a)$ Амплитуда осцилляции $\left(I_{\max }-I_{\min }\right)$ при $V_{b} \sim 0$ при освещении структуры светодиодами с $\lambda$ от 650 до $405 \mathrm{~nm}$ при условии равенства $\left.I_{\text {fon }}=1 \mathrm{nA} ; b\right)$ сравнение расчетных и экспериментальных величин положения осцилляций по $V_{b}$.

энергией $E_{\mathrm{C}}$, а величина неосциллирующей компоненты фототока - аддитивными вкладами токов носителей, возбуждаемых светом определенной длины волны в остальных областях активной части гетероструктур.

Подтверждением того, что осцилляции фототока от напряжения смещения в наших $p-i-n$-структурах происходят благодаря диффузии электронов, возбужденных светом в $p^{+}$-области и пришедших к краю треугольной квантовой ямы с энергией $E_{\mathrm{C}}$, является и величина фотоосцилляций для $\lambda=405 \mathrm{~nm}$, бо́льшая, чем для $\lambda=650 \mathrm{~nm}$, при фиксированной величине неосциллирующего тока (см. рис. 3,a). Поскольку „фоновый ток“ является суммой нерезонансного тока через ТКЯ и тока носителей рожденных в $i$ - и $n$-областях, то с увеличением длины волны света он растет из-за все большего проникновения света вглубь структуры и роста числа пар, сгенерированных в $i$-слоях, что приводит к относительному уменьшению амплитуды осцилляций фототока. На рис. 4, $a$ представлены величины $\left(I_{\max }-I_{\min }\right)$ для осцилляции около $V_{b} \sim 0$ при освещении структуры светом с $\lambda$ от 650 до $405 \mathrm{~nm}$, так что „фоновый токgrqq был равен $1 \mathrm{nA}$. Монотонное относительное увеличение амплитуды осцилляции с уменьшением $\lambda$ объяснимо отмеченным выше уменьшением $I_{\text {fon }}$ из-за все меньшего проникновения света вглубь структуры и уменьшения числа пар, сгенерированных в $i$-слоях. 
Хорошее совпадение лестницы напряжений $V_{b}$, соответствующей экстремумам осцилляций, с последовательностью моментов совпадения $E_{j}$ и $E_{\mathrm{C}}$ показано уже в нашей первой работе [9], и аналогичный расчет, произведенный нами для данной гетероструктуры, представлен на рис. $4, b$.

Но если в старой модели в этот момент происходит резкое падение фототока, то в предположении резонансного туннелирования пришедших из глубины $p^{+}$-области фотовозбужденных электронов такому моменту будет соответствовать максимум фототока. Электростатическая модель, используемая нами для расчета моментов совпадения $E_{j}$ и $E_{\mathrm{C}}[9,10]$, не дает нам возможности сделать выбор между этими двумя механизмами осцилляций, так как мы не можем рассчитать положение минимумов или максимумов осцилляций с точностью в полпериода из-за невозможности корректного учета накопления заряда в AlAs-барьере на дефектах и квантовых точках в барьере и сложности измерения первой осцилляции в момент формирования ТКЯ. Но даже эти расчеты подтверждают, что положение экстремумов осцилляций фототока определяются исключительно дизайном ТКЯ.

\section{4. Заключение}

Как результат, нами изучено поведение квантовых осцилляций фототока в $p-i-n$-гетероструктурах GaAs/AlAs при воздействии на них светом с длинами волн $\lambda$ в интервале от 875 до $405 \mathrm{~nm}$. Продемонстрирована доминирующая роль канала диффузии фотовозбужденных электронов из сильнолегированного $p^{+}$-слоя в процессе формирования осцилляций фототока от напряжения смещения и определяющий вклад этого канала в полный ток через структуру.

\section{Благодарности}

Авторы выражают благодарность М. Хенини (М. Неnini, University of Nottingham, UK) за изготовление образцов.

\section{Финансирование работы}

Работа выполнена в рамках Госзадания № 075-0035521-00.

\section{Конфликт интересов}

Авторы заявляют, что у них нет конфликта интересов.

\section{Список литературы}

[1] K.A. Patel, J.F. Dynes, A.W. Sharpe, Z.L. Yuan, R.V. Penty, A.J. Shields. Electron. Lett. 48, 2, 111 (2012).

[2] X. Shang, Y. Yu, M. Li, L. Wang, G. Zha, H. Ni, H. Pettersson, Y. Fu, Z. Niu. J. Appl. Phys. 118, 24, 244503 (2015).
[3] D. Inoue, Y. Wan, D. Jung, J. Norman, C. Shang, N. Nishiyama, S. Arai, A.C. Gossard, J.E. Bowers. Appl. Phys. Lett. 113, 9, 093506 (2018).

[4] S.M. Sze. Physics of Semiconductor Devices. Wiley, N.Y. (1981). P. 749-765.

[5] R.E. Nahory. Phys. Rev. 178, 3, 1293 (1969).

[6] J. Allam, F. Capasso, M.B. Panish, A.L. Hutchinson. Appl. Phys. Lett. 49, 12, 707 (1986).

[7] M.V. Baranovskiy, G.F. Glinskii. J. Phys.: Conf. Ser. 461, 1, 012039 (2013).

[8] A.E. Belyaev, S.A. Vitusevich, L. Eaves, P.C. Main, M. Henini, A. Forster, W. Reetz, S.V. Danylyuk. Nanotechnol. 13, 1, 94 (2002).

[9] E.E. Vdovin, M. Ashdown, A. Patane, L. Eaves, R.P. Campion, Yu.N. Khanin, M. Henini, O. Makarovsky. Phys. Rev. B 89, 20, 205305 (2014).

[10] Ю.Н. Ханин, Е.Е. Вдовин, О. Макаровский, М. Хенини. Письма в ЖЭТФ 102, 11, 830 (2015).

[11] Е.Е. Вдовин, Ю.Н. Ханин. Письма в ЖЭТФ 113, 9, 605 (2021).

[12] H.C. Casey, D.D. Sell, K.W. Wecht. J. Appl. Phys. 46, 1, 250 (1975).

[13] M.L. Leadbeater, E.S. Alves, L. Eaves, M. Henini, O.H. Hughes, A. Celeste, J.C. Portal, G. Hill, M.A. Pate. J. Phys.: Condens. Matter 1, 29, 4865 (1989).

Редактор Е.В. Толстякова 